\title{
EFFECTS OF AIR INTAKE PRESSURE ON THE ENGINE PERFORMANCE, FUEL ECONOMY AND EXHAUST EMISSIONS OF A SMALL GASOLINE ENGINE
}

\author{
Nik Rosli Abdullah ${ }^{1}$, Nafis Syabil Shahruddin ${ }^{1}$, Rizalman Mamat ${ }^{2}$, Aman Mohd. \\ Ihsan Mamat ${ }^{1}$ and Aminuddin Zulkifli ${ }^{1}$ \\ ${ }^{1}$ Faculty of Mechanical Engineering, Universiti Teknologi MARA, \\ 40450 Shah Alam, Selangor, Malaysia. \\ Phone: +603 - 55435150 ; Fax: 03-5543 5160 \\ E-mail: nikrosli@salam.uitm.edu.my \\ ${ }^{2}$ Faculty of Mechanical Engineering, Universiti Malaysia Pahang, \\ 26600 Pekan, Pahang, Malaysia. \\ Phone: +609 - 4246275 ; Fax: +609 - 4246222 \\ E-mail: rizalman@ump.edu.my
}

\begin{abstract}
This study presents the engine performance, fuel economy and exhaust emissions at variations of air intake pressure. In a carburetor system, the air intake pressure is influenced by the degree of opening throttle plate and the Venturi effect which draws the fuel to the combustion chamber. The experimental work was carried out on variations of engine speed and load using a single cylinder four stroke gasoline engine attached to a dynamometer. The measured exhaust emission compositions are used to determine the mode of combustion. The results show that the standard air intake system resulted in rich combustion which then led to incomplete combustion, which was caused by less availability of air for the combustion process. Eliminating the air filter reduces the air flow restriction in the air intake system resulting in better combustion and less unburned components due to higher air availability. Higher air intake pressure is better at increasing the efficiency of combustion within a limited time to improve fuel economy, power output and exhaust emissions. Better combustion also leads to reduced unburned components such as carbon $(\mathrm{C})$, hydrogen $\left(\mathrm{H}_{2}\right)$, carbon monoxide $(\mathrm{CO})$ and hydroxide $(\mathrm{OH})$, which results in cleaner emissions.
\end{abstract}

Keywords: Air intake pressure; air filter; air fuel ratio; fuel consumption; exhaust emissions.

\section{INTRODUCTION}

Better performance with improved fuel economy and exhaust emissions are two different objectives which are difficult to achieve together. Introducing more air into the air fuel mixture can improve combustion efficiency to enhance engine performance(Kamil, Rahman, \& Bakar, 2011; Sundar Raj \& Sendilvelan, 2010). The simplest way to increase the air flow rate is to reduce the air flow restriction through the air filter element. Modern internal combustion (IC) engines use an air intake system for filtering the atmospheric air into clean air and routing the clean air into the combustion chambers (Abdullah et al., 2009; Bhaskar, Nagarajan, \& Sampath, 2010; Mohanamurugan \& Sendilvelan, 2011; Van Basshuysen \& Schäfer, 2004; Yusaf, Baker, Hamawand, \& Noor, 2013). The main part of an air intake system is the air 
filter, which lowers the pollutant in the air intake to an acceptable level but on the other hand increases the flow restriction of the air intake.

The combustion process is a very fast process and is an oxidizing chemical reaction that chemically combines fuel with oxygen in the atmospheric air which releases huge energy in the form of heat (Radcliff, Roark, \& Koloski, 2009; Rahim, Mamat, Taib, \& Abdullah, 2012; Saad \& Bari, 2013). The ignition event is an engine operation period where the charge ignites and rapidly oxidizes during a chemical reaction to release heat energy. The complete combustion will burn all the combustible chemical components in fuel completely, as explained in Eq. (1) (Cengel, Boles, \& Kanoglu, 2007). Incomplete combustion is identified when there is unburned fuel or components such as $\mathrm{C}, \mathrm{H}_{2}$, $\mathrm{CO}$, or $\mathrm{OH}$.

$$
\mathrm{CH}_{4}+2\left(\mathrm{O}_{2}+3.76 \mathrm{~N}_{2}\right) \rightarrow \mathrm{CO}_{2}+2 \mathrm{H}_{2} \mathrm{O}+7.52 \mathrm{~N}_{2}
$$

A clogged air filter will increase fuel consumption since the air fuel ratio becomes richer due to insufficient air supply. This is only true for carbureted engines because the closed-loop control of the fuel injection system is able to control the amount of injected fuel based on the reduced volume of air intake (Norman, Huff, \& West, 2009; Yusaf, Hamawand, Baker, \& Najafi, 2013)The carburetor relies only on the vacuum effect that draws an amount of fuel with respect to the air flow through the Venturi. In closed loop control of the fuel injection system, the system uses the data from the exhaust sensor to maintain the lean air fuel ratio with the respective amount of air. The fuel economy of a fuel injection engine is thus not influenced by the condition of the air filter. The Subaru Robin EX17 engine used in this project uses a carburetor and is thus expected to produce results demonstrating that fuel consumption is influenced by the characteristics of air intake. Increments in engine brake specific fuel consumption (BSFC) and reductions in engine efficiency are due to higher pressure drops in the inlet manifold at part load and low load. Particularly in part load, the $\mathrm{NO}_{\mathrm{x}}$ emission is mainly influenced by the air fuel ratio (AFR) compared to ignition delay when greater drops in pressure will enhance the $\mathrm{NO}_{\mathrm{x}}$ emission. With both ultra-low sulfur diesel (ULSD) and rapeseed methyl ester (RME), the engine combustion and emissions are affected by the magnitude of the inlet manifold pressure drop (Pulkrabek, 2004). The consequences of reducing engine altitude, increasing air intake pipe diameter, increasing atmospheric pressure and increasing engine speed are the reduction of both carbon monoxide $(\mathrm{CO})$ and hydrocarbon $(\mathrm{HC})$ with constant oxygen $\left(\mathrm{O}_{2}\right)$ and carbon dioxide $\left(\mathrm{CO}_{2}\right)$ (Shannak, Damseh, \& Alhusein, 2005; Yusaf, Baker, et al., 2013). HC emission reduction is due to an improved combustion process caused by larger air intake pipe diameter and higher engine speed. The $\mathrm{CO}$ emission is affected by the amount of fuel which is usefully burnt based on an amount of oxygen during the combustion process. Continuous variable intake plenum length is applied to match the suitable length of intake plenum with respective engine speed for enhancing engine performance characteristics, especially fuel consumption, through all operating conditions. A longer intake plenum length is suitable for low RPM ranging from 1000 to 3000 on average while a shorter intake plenum length is generally suitable for RPM higher than 4000 (Ceviz \& Akın, 2010). In this project, air intake pressure is observed after the air filter point of both variables, which is the air intake system with air filter and the air intake system without air filter. The main point is to identify the best characteristics of air intake for better engine performance with lower fuel consumption and exhaust emissions. To protect the engine condition while achieving the project 
objectives, the experiment is run in a clean and protected environment for cleaner and less polluted air when running the experiment on the air intake system without air filter.

\section{EXPERIMENT SETUP AND PROCEDURE}

The experiment was carried out using a $169 \mathrm{~cm}^{3}$ single cylinder gasoline engine mounted with $5 \mathrm{~kW}$ eddy current type electric dynamometer. Each experiment variable is running at increased engine speed and load to study the effects throughout the engine operation condition by obtaining various output data. The overall experiment instrument layout is explained in Figure 1.

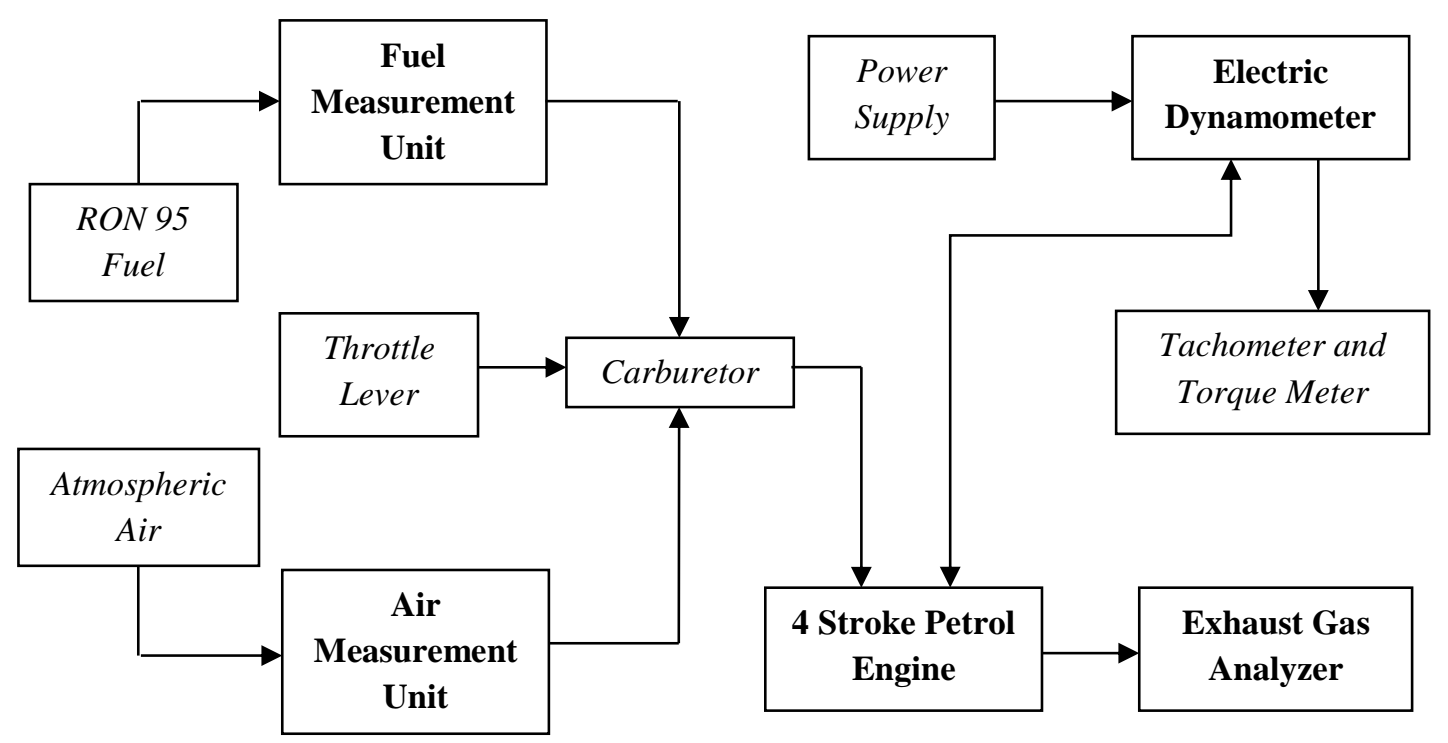

Figure 1. Overall experiment instrument layout.

The engine was a Subaru Robin EX17 single cylinder gasoline engine with the potential to produce $4.2 \mathrm{~kW}$ of maximum power and mounted with a PS-DEC-1 $5 \mathrm{~kW}$ small engine electric dynamometer eddy current type capable of up to 4000rpm maximum speed on the engine test bench. A PS-SOE-1B fuel tank with graduated tube was used for measuring the fuel consumption. A PS-SOE-2 air consumption device with manometer was used to measure the air intake pressure and temperature. The manometer is from Dwyer, and senses the air intake pressure. The manometer fluid used had a specific gravity of 0.826 which makes its density $826 \mathrm{~kg} / \mathrm{m}^{3}$. The instrument panel of the PS-SOE-7 electronic digital temperature meter with six thermocouples and selector switch equipped with torque meter and tachometer gives the temperature reading at 6 points, the magnitude of load applied and engine speed. The 6 point temperature readings are taken at air cooler inlet, exhaust port, air cooler outlet, engine oil, air intake and ambient air. The energy supplied to the dynamometer was given by a Lodestar power supply model 8112 capable of producing 60 volts and 5 ampere at maximum. A hygro-thermometer was used to measure the atmospheric air temperature and humidity, with its sensor placed near to the air filter to obtain the exact data for avoiding effects from surrounding elements. An MRU 95/3 CD Flue Gas Analyzer was used to analyze the exhaust emission compositions. It able to produce the emission composition volume percentage in unit $\%$ vol and ppm for $\mathrm{O}_{2}, \mathrm{CO}_{2}, \mathrm{CH}_{4}, \mathrm{CO}, \mathrm{SO}_{2}, \mathrm{NO}$, 
and $\mathrm{NO}_{\mathrm{X}}$ compositions and the temperature of exhaust gas and environment. The $\mathrm{CH}_{4}$ and $\mathrm{CO}$ sensors in this gas analyzer were malfunctioning.

Table 1. Fuel properties

\begin{tabular}{lc}
\hline Research Octane Number & 95 \\
\hline Density at $15^{\circ} \mathrm{C}, \mathrm{kg} / \mathrm{m}^{3}$ & 752.5 \\
Kinematic Viscosity, $\mathrm{m}^{2} / \mathrm{s}$ & $5 \times 10^{-6} \mathrm{~m}^{2} / \mathrm{s}$ \\
Lower Calorific Value, MJ/kg & 42.7 \\
Higher Calorific Value, MJ/kg & 45.7 \\
\hline
\end{tabular}

Table 2. Subaru Robin EX17 engine specifications

\begin{tabular}{lc}
\hline Type & $\begin{array}{c}\text { Air-Cooled, 4-Cycle, Slant Single } \\
\text { Cylinder, OHC, Horizontal PTO Shaft }\end{array}$ \\
\hline Bore x Stroke (mm) & 67 x 48 \\
$\begin{array}{l}\text { Displacement (cc) } \\
\text { Continuous Output } \\
\text { (kW/rpm) }\end{array}$ & 169 \\
$\begin{array}{l}\text { Maximum Output } \\
\text { (kW/rpm) }\end{array}$ & $2.6 / 3000 \& 2.9 / 3600$ \\
Maximum Torque & $4.2 / 4000$ \\
(Nm/rpm) & $11.3 / 2500$ \\
\hline
\end{tabular}

On each run, multiple data such as temperatures, atmospheric air temperature and humidity, engine speed and load, voltage and current supplied to dynamometer, fuel consumption and exhaust emissions were taken. The fuel consumption in liters per hour (1/hour) was measured by dividing the volume of fuel consumed by a period of time as explained in Equation 3.

$$
\dot{V}_{K}=\left(\frac{V_{f u e l}(\mathrm{ml})}{1000}\right) \div\left[\left(\frac{t_{(\mathrm{min})}}{60}\right)+\left(\frac{t_{(\mathrm{sec})}}{3600}\right)\right] \quad(l / \text { hour })
$$

By using the MRU 95/3 CD Flue Gas Analyzer, at least 40 seconds from the time the probe senses the exhaust gases is needed for the gas analyzer to produce consistent and reliable data for the exhaust emission composition. According to its manual, the $\mathrm{O}_{2}$ sensor needs approximately 20 seconds, the $\mathrm{CO}$ sensor needs 30 seconds, the $\mathrm{SO}_{2}$ sensor needs 30 seconds and the NO sensor needs 30 seconds (Mohanraj \& Kumar, 2013). The gas analyzer probe was located $120 \mathrm{~cm}$ from the exhaust port because the exhaust port was connected to a long pipe for channeling the exhaust gas out of the lab so as to avoid human suffocation. In obtaining the absolute air intake pressure, the atmospheric pressure is ignored as it is assumed to be constant through the entire experiment process. Only the air intake gauge pressure is measured using the water column height, $\mathrm{h}$, from the manometer as explained in Equation 5. The point at which the air intake gauge pressure was measured was $23 \mathrm{~cm}$ after the air filter. After 5 runs, the spark plug with the gas analyzer's probe and filter were cleaned, thus maintaining the engine efficiency and consistency of the gas analyzer.

$$
P_{\text {gauge }}=\rho_{\text {fluid }} \cdot g \cdot h
$$




\section{RESULTS AND DISCUSSION}

\section{Analysis of Output Data for Constant Engine Speed}

This analysis of data was carried out based on constant engine speed. The approach to this data analysis was used in order to study the pattern of output data behavior towards the manipulation of load at constant engine speed.

Table 3. The constant loads and engine speeds for output data analysis

\begin{tabular}{ccccc}
\hline \multicolumn{2}{c}{ Condition } & Engine Speed, rpm & Torque, Nm & Power, $\mathrm{kW}$ \\
\hline Constant & 1 & 3000 & 1 & 0.314 \\
Engine & 2 & 3000 & 2 & 0.628 \\
Speed & 3 & 3000 & 4 & 1.257 \\
\hline
\end{tabular}

\section{Fuel Consumption}

As seen in Figure 2, the fuel consumption clearly decreases for both variables (without air filter and with air filter) based on constant engine speed analysis. Fuel consumption decreased by approximately $13.1 \%$, from 1.2331 /hour to 1.071 1/hour for the variable with air filter. The reduction for the variable without air filter was only about $10.8 \%$, from $1.191 \mathrm{l} /$ hour to $1.062 \mathrm{l} /$ hour. The reduction in fuel consumption is due to the increasing load acting on the constant engine speed which lowers the engine speed and consumes less fuel.

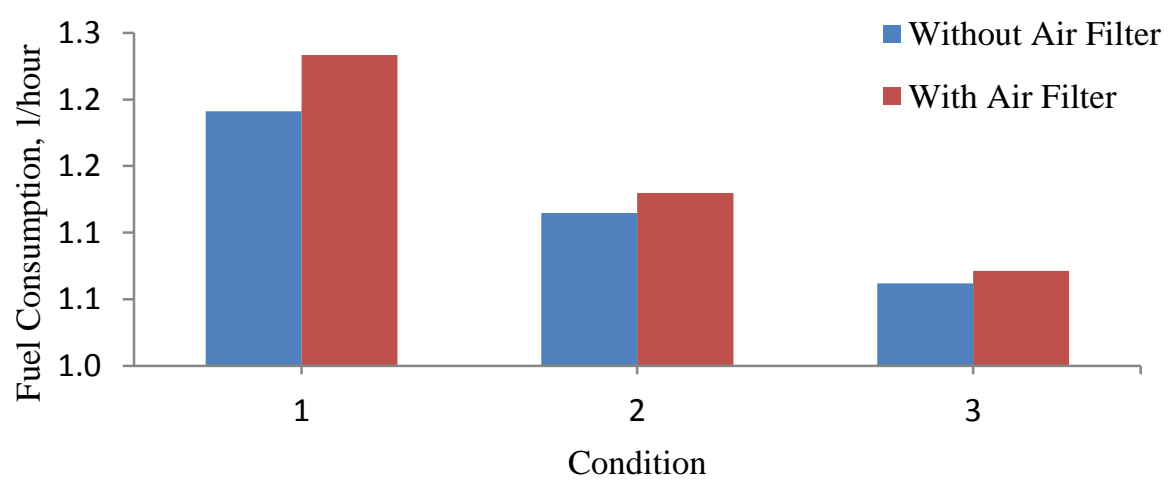

Figure 2. Graph of fuel consumption at constant engine speed

Fuel consumption is affected by the air fuel ratio where leaner combustion will consume less fuel and richer combustion will consume more fuel (Sayin, Gumus, \& Canakci, 2010). Without an air filter, the discharge air capacity is greater than the variable with the air filter. In the case of constant engine speed, the increasing magnitude of load will reduce the fuel consumed by the engine, because a larger load will reduce the engine speed which consumes less fuel. In reality, the more a load increases, the more fuel is being consumed because we usually increase the throttle opening in order to increase the engine speed to overcome the higher load acting on the vehicle. 


\section{Air Intake Gauge Pressure}

The differences between both variables of air intake gauge pressures are in Conditions 2 and 3 which are $0.54 \mathrm{~Pa}$ and $1.621 \mathrm{~Pa}$ respectively. In addition, the air intake gauge pressure for Condition 1 is similar for both variables, without air filter and with air filter, at $17.827 \mathrm{~Pa}$. The reason for this similarity is that when the engine is running at high speed, for example $3000 \mathrm{rpm}$, and being loaded with $1 \mathrm{Nm}$ of load, the engine is still capable of maintaining high speed but this must be less than $3000 \mathrm{rpm}$, and that final speed requires a large air intake flow rate which is able to overcome the restriction of the air filter media. For this reason, the air intake gauge pressure between both variables, without air filter and with air filter, is very different for Condition 3 . Under Condition 3, the engine speed is 3000rpm and the engine is loaded with $4 \mathrm{Nm}$ which reduces its final engine speed, which is still greater than that for Condition 1 . The final lower engine speed in Condition 3 requires a small air intake flow rate which can be further restricted by the air filter media which further decreases the air intake gauge pressure in the variable with air filter.

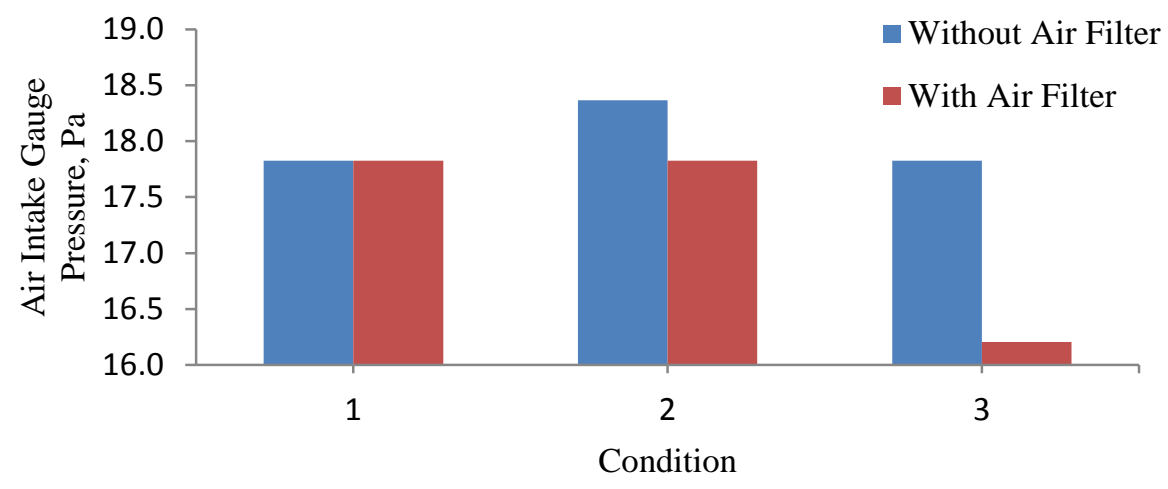

Figure 3. Graph of air intake gauge pressure at constant engine speed

The engine speed is the main factor affecting the air intake pressure in a naturallyaspirated engine. Higher air intake pressure will occur with greater engine speed. At a higher engine speed, however, the time period for the air fuel mixture to enter the cylinder is very brief. This leads to an insufficient supply of air fuel mixture in the cylinder during higher engine speeds, which can be overcome by using a forced induction system and also variable valve timing and lifting. In a forced induction engine, the air intake pressure is boosted with the help of a compressor which is rotated by the exhaust gas in a turbocharged engine or crankshaft in a supercharged engine. The gas exchange in the combustion chamber is can also be optimized, with the overlap intake and exhaust valves opening for a limited period at high engine speed. When both intake and exhaust valves are open, the low pressure caused by the opening exhaust valve helps the air fuel mixture to flow easily into the combustion chamber, which is very useful at high engine speeds. In terms of volumetric efficiency, supplying a higher amount of air into the cylinder is able to increase the engine power output. The difficulty is that to obtain a greater volume of gaseous air that reacts with the fuel is much harder than to obtain a smaller volume of liquid fuel in the engine cylinder. Theoretically, the mass of induced air into the cylinder for each cycle is equal to the atmospheric air density times the engine cylinder displacement volume. The reality is that with the limited period of cycle available, and the restricted air flow caused by the 
air filter, intake manifold and intake valve; the exact amount of air is usually less than the theoretical volume (Pulkrabek, 2004).

\section{$\mathrm{CO}_{2}$ Emissions}

For the analysis of constant engine speed, there is a similarity in the volume percentage of carbon dioxide composition in Condition 2 for both variables, $3.8 \mathrm{vol} \%$. Only $2.4 \%$ extra volume percentage of carbon dioxide emission for the variable without air filter respective to the variable with air filter on Condition 1. For Condition 3, the variable without an air filter has an extra $12.5 \%$ in volume percentage of carbon dioxide emissions than the variable with an air filter.

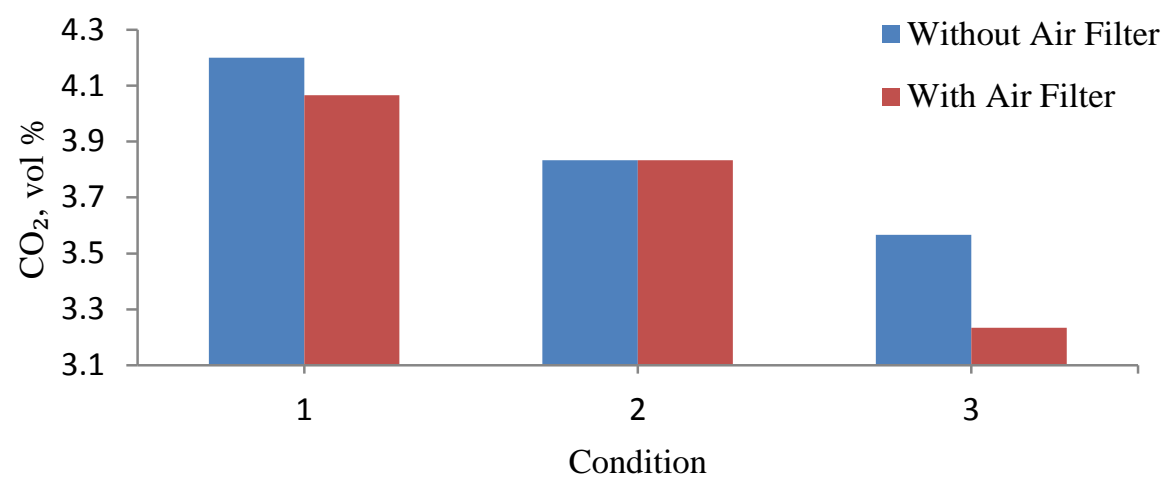

Figure 4. Graph of $\mathrm{CO}_{2}$ composition at constant engine speed

The percentage of carbon dioxide volume is higher without an air filter and lower with an air filter. More complete combustion produces more carbon dioxide as the oxygen inside air combines with the carbon inside the fuel. The volume percentage of carbon dioxide is therefore higher without the air filter as it induces more air into the carburetor forming a leaner air fuel mixture for better combustion. The condition with the air filter will have a slightly lower amount of carbon dioxide because the combustion quality is lower due to the richer air fuel mixture caused by less induced air in the carburetor. The higher amount of $\mathrm{CO}_{2}$ is an indication of better combustion of fuel in the combustion chamber which also relates to the exhaust gas temperature (Mohanraj \& Kumar, 2013). $\mathrm{CO}_{2}$ emission will increase because of better reaction between the fuel and oxygen during the combustion process (Sayin et al., 2010), but Sayin et al. (2010) enhanced the reaction between fuel and oxygen by means of advanced injection timing in order to obtain better combustion.

\section{$N O_{x}$ Emissions}

The variable without an air filter produced more $\mathrm{NO}_{\mathrm{x}}$ than the variable with an air filter. The $\mathrm{NO}_{\mathrm{x}}$ composition without an air filter fluctuated from Condition 1 to 3 , but in the variable with an air filter, the $\mathrm{NO}_{\mathrm{x}}$ formation decreased from Condition 1 to 3 . The most obvious difference between both variables in this $\mathrm{NO}_{\mathrm{x}}$ formation was in Condition 3, where the $\mathrm{NO}_{\mathrm{x}}$ composition of the variable without an air filter was almost $30 \%$ more than the variable with an air filter. The $\mathrm{NO}_{\mathrm{x}}$ formation was similar for both variables in Condition 1, and for Condition 2; there was only $3.4 \%$ additional $\mathrm{NO}_{\mathrm{x}}$ composition for the variable without an air filter compared with the variable with an air filter. 


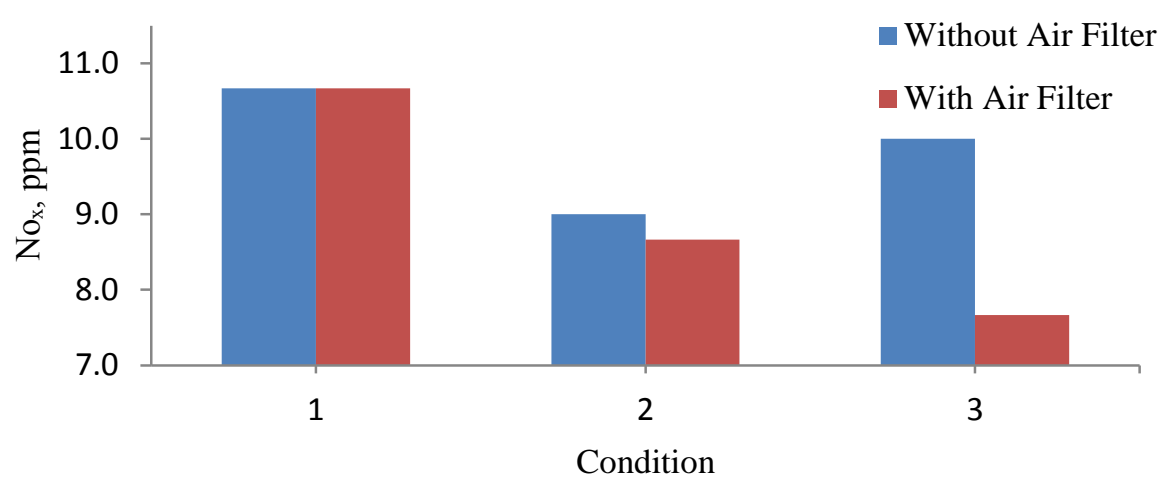

Figure 5. Graph of $\mathrm{NO}_{\mathrm{X}}$ composition at constant engine speed

The Zeldovich mechanism is supported with this pattern of $\mathrm{NO}_{\mathrm{x}}$, in which $\mathrm{NO}_{\mathrm{x}}$ formation is influenced by the maximum temperature and the pressure of the combustion process (Radcliff et al., 2009). The improved combustion process causes higher in-cylinder temperature and pressure on the variable without an air filter, which then leads to the higher $\mathrm{NO}_{\mathrm{x}}$ composition (Abdullah et al., 2009). By comparing the theory of the Zeldovich mechanism with the experiment result, it is thus agreed that the increase in combustion pressure and temperature in the condition without an air filter increases the formation of $\mathrm{NO}_{\mathrm{x}}$. Increasing the pressure drop through the air intake system makes less efficient combustion and reduces the number of $\mathrm{NO}_{\mathrm{x}}$ formations.

\section{Exhaust Gas Temperature}

The exhaust gas temperature for the variable without an air filter fluctuated from Conditions 1 until 3. For the variable with an air filter, the exhaust gas temperature decreased from Condition 1 until 3, as the load increased with the constant engine speed. The biggest difference was in Condition 2, where there was a $50 \%$ increment in exhaust gas temperature for the variable without an air filter, based on exhaust gas temperature of variables with air filter. There was only a small increment in exhaust gas temperature for the variable without an air filter compared to the variable with an air filter for Conditions 1 and 3 which are $17.37 \%$ and $14.16 \%$ respectively.

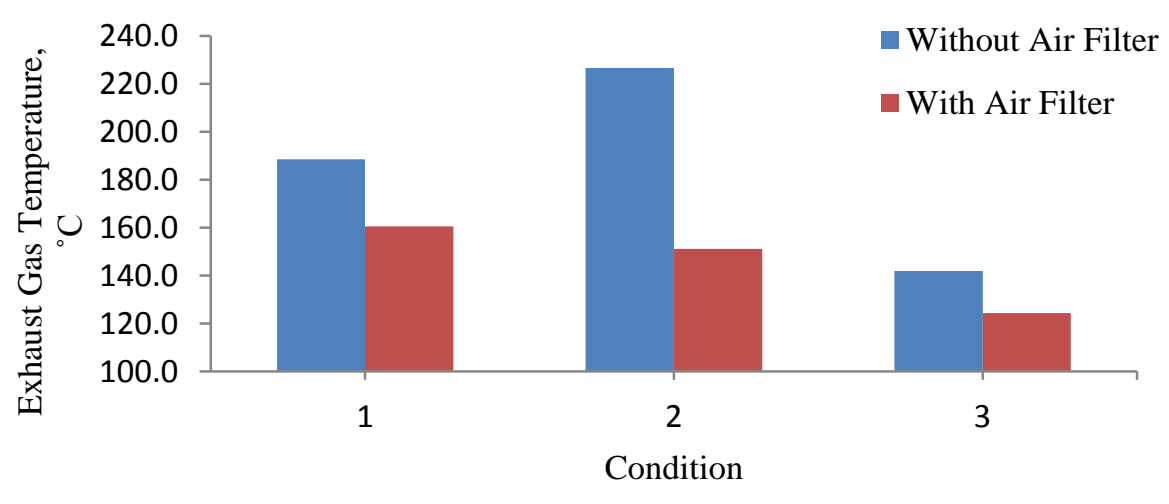

Figure 6. Graph of exhaust gas temperature at constant engine speed

Energy is released in many forms and one is heat produced during the combustion process. More efficient combustion with better chemical reactions will produce more energy, such as heat, which raises the exhaust gas temperature. A higher exhaust gas 
temperature leads to higher exhaust gas pressure as explained in the ideal-gas equation of state, $P v=m R T$. The temperature of exhaust gas reflects the in-cylinder temperature which is directly proportional to the in-cylinder pressure. According to (Abdullah et al., 2009), the exhaust gas temperature increases along with the increased injection pressure due to greater heat being generated inside the combustion chamber, caused by more complete combustion (Abdullah et al., 2009). Both higher injection pressure and higher air intake pressure lead to a better combustion process and higher exhaust gas temperature. The difference is that the higher air intake pressure improves the combustion process by causing the leaner air fuel mixture to be combusted more efficiently while the higher injection pressure improves the combustion process with smaller fuel droplet particles that are able to penetrate more deeply through the pressurized air inside the CI engine combustion chamber.

\section{CONCLUSIONS}

The difference in air intake pressure caused by variables with air filter and without air filter influences the engine behavior in respect of engine performance, fuel consumption and exhaust emissions. The combustion process burns all combustible elements in the fuel by combining carbon and hydrogen with oxygen. To extract more energy from the combustion process, it needs to form a leaner air fuel mixture. The large amount of air increases the potentiality of fuel chemical elements to be burned with oxygen. As a result, the engine performance and fuel economy are increased while the unburned exhaust emission components are reduced.

I. Higher air intake pressure increases the engine performance against the applied load better than lower air intake pressure.

II. Higher air intake pressure improves the fuel economy by introducing a leaner air fuel mixture. The fuel consumption is directly influenced by the air fuel ratio.

III. Higher air intake pressure supplies more $\mathrm{O}_{2}$ to be combined with fuel elements in improving the combustion process

IV. Higher air intake pressure increases the $\mathrm{CO}_{2}$ emissions by optimizing the chemical reaction between carbon from fuel with the oxygen from air.

V. Higher air intake pressure increases the $\mathrm{NO}_{\mathrm{X}}$ emission. The Zeldovich mechanism explains that the $\mathrm{NO}_{\mathrm{x}}$ formation is directly proportional to the maximum pressure and temperature of the combustion process.

VI. Higher air intake pressure enhances the conversion of chemical energy into heat energy which raises the exhaust gas temperature.

\section{ACKNOWLEDGEMENTS}

The authors would like to thank the Ministry of Higher Education (MOHE) and Research Management Institute of the Universiti Teknologi MARA (UiTM), Malaysia for financial support under grant awards 600-RMI/ST/FGRS 5/3Fst (32/2011).

\section{REFERENCES}

Abdullah, N., Mamat, R., Rounce, P., Tsolakis, A., Wyszynski, M., \& Xu, H. (2009). Effect of injection pressure with split injection in a v6 diesel engine. Energy, 2009, 03-31. 
Bhaskar, K., Nagarajan, G., \& Sampath, S. (2010). Experimental investigation on cold start emissions using electrically heated catalyst in a spark ignition engine. International Journal of Automotive and Mechanical Engineering, 2, 105-118.

Cengel, Y. A., Boles, M. A., \& Kanoglu, M. (2007). Thermodynamics: An engineering approach (si units) (Vol. 6). Singapore: McGraw-Hill New York.

Ceviz, M. A., \& Akın, M. (2010). Design of a new si engine intake manifold with variable length plenum. Energy Conversion and Management, 51(11), 22392244.

Kamil, M., Rahman, M. M., \& Bakar, R. A. (2011). Performance evaluation of external mixture formation strategy in hydrogen fueled engine. Journal of Mechanical Engineering and Sciences, 1, 87-98.

Mohanamurugan, S., \& Sendilvelan, S. (2011). Emission and combustion characteristics of different fuel in a hcci engine. International Journal of Automotive and Mechanical Engineering, 3, 279-292.

Mohanraj, T., \& Kumar, K. M. M. (2013). Operating characteristics of a variable compression ration engine using esterified tamanu oil. International Journal of Green Energy, 285 - 301.

Pulkrabek, W. W. (2004). Engineering fundamentals of the internal combustion engine: Pearson Prentice Hall.

Radcliff, R. B., Roark, D. L., \& Koloski, D. R. (2009). Small engines (3 ed.): American Technical Publishers.

Rahim, R., Mamat, R., Taib, M. Y., \& Abdullah, A. A. (2012). Influence of fuel temperature on a diesel engine performance operating with biodiesel blended. Journal of Mechanical Engineering and Sciences, 2, 226-236.

Saad, I., \& Bari, S. (2013). Cfd investigation of in-cylinder air flow to optimize number of guide vanes to improve ci engine performance using higher viscous fuel. International Journal of Automotive and Mechanical Engineering, 8, 10961107.

Sayin, C., Gumus, M., \& Canakci, M. (2010). Effect of fuel injection timing on the emissions of a direct-injection (di) diesel engine fueled with canola oil methyl ester-diesel fuel blends. Energy and Fuels, 24(4), 2675-2682.

Shannak, B., Damseh, R., \& Alhusein, M. (2005). Influence of air intake pipe on engine exhaust emission. Forschung im Ingenieurwesen, 70(2), 128-132.

Sundar Raj, C., \& Sendilvelan, S. (2010). Effect of oxygenated hydrocarbon additives on exhaust emission of a diesel engine. International Journal of Automotive and Mechanical Engineering, 2, 144-156.

Van Basshuysen, R., \& Schäfer, F. (2004). Internal combustion engine handbookbasics, components, systems and perspectives (Vol. 345): SAE International.

Yusaf, T., Baker, P., Hamawand, I., \& Noor, M. M. (2013). Effect of compressed natural gas mixing on the engine performance and emissions. International Journal of Automotive and Mechanical Engineering, 8, 1416-1429.

Yusaf, T., Hamawand, I., Baker, P., \& Najafi, G. (2013). The effect of methanol-diesel blended ratio on ci engine performance. International Journal of Automotive and Mechanical Engineering, 8, 1385-1395. 